\section{International Union of Geological Sciences: What is it and what is the role of the United States?}

Farouk El-Baz, Boston University, Center for Remote Sensing, 725 Commonwealth Ave., Boston, Massachusetts 02215-1401, farouk@crsa.bu.edu

During August 2004, Florence, Italy, was host to the 32nd International Geological Congress (IGC), an eight-day meeting that attracted 8,000 geologists from most of the world's nations. The surroundings of Florence offered many distractions to the geologists attending the IGC, including unique geology, a pleasant environment, and many tourist attractions. Despite these distractions, the remarkably organized technical sessions were well attended and many new friendships (and potential collaborations) were made. Some 650 U.S. geologists attended the IGC, which was sponsored by the International Union of Geological Sciences (IUGS). Behind the scenes, meetings required much work and some diplomacy by representatives from the 117 nations in attendance.

Such international fora are, in some respects, the geosciences equivalent to the United Nations. Therefore, it is appropriate to ask: How is the United States represented in the IUGS?

The U.S. National Academy of Sciences (NAS) represents the United States to the IUGS, which is an umbrella organization that includes national representatives and 34 affiliated organizations (including GSA, the American Geophysical Union, and the American Association of Professional Geologists). The U.S. National Committee for the International Union of Geological Sciences (USNC/IUGS) serves as a liaison between U.S. geoscience organizations and the IUGS and seeks their input for IUGS programs, actions, and activities. The USNC also coordinates U.S. participation in furthering the goals and work of the IUGS.

The USNC represents the NAS in the IUGS International Geoscience Program, which was developed jointly by IUGS and the United Nations Educational, Scientific and Cultural Organization to facilitate the collaboration of multinational research teams involved in research topics of global interest. The committee also serves the NAS in an advisory capacity, consulting with U.S. Government agencies concerning the needs and opportunities of international geological science.
The USNC includes members from academia, research institutions, government agencies, and private industry. USNC members provide information to the U.S. geoscience community about IUGS activities and sponsor symposia at scientific association meetings on topics of international interest, such as biodiversity, sustainability, and megacities.

A major thrust of the IUGS is the Year of Planet Earth, which is a multidisciplinary, international project that involves the expertise available from the different entities of IUGS and its 37 affiliated organizations. The plan for the Year of Planet Earth has been submitted to the United Nations for its adoption and will likely be declared by that body. The purpose of the Year of Planet Earth is "....intended to be a vigorous international program, the principal goal of which is to demonstrate the enormous potential of the Earth sciences to lay the foundations of a safer, healthier and wealthier society. This goal leads naturally to the Year's subtitle: Earth sciences for society."

The Year of Planet Earth will likely occur in 2007-2008. Much of the activity will be dedicated to outreach programs that demonstrate the importance of the geosciences to society. Collaborative research programs will most likely follow the approach used by the International Geoscience Program.

The Year of Planet Earth is only one of many issues that the USNC addresses. Another example of international cooperation is the establishment of better communications between U.S. scientists and geoscience organizations in the Middle East, the Islamic world, Asia, and South America. Symposia at national and international meetings that have been organized by the USNC have included such topics as sustainability, social equity and the geosciences, and the role of the earth sciences in national security.

The United States' representation in the IUGS is paramount for facilitating international connections in our profession, and there is no question that the United States benefits greatly from official participation in international scientific conferences such as the IGC. As one Russian colleague stated, the IGC is "geology without borders." This is particularly important at a time when U.S. foreign policy is not universally supported. Science and technology are areas in which the United States is still held in esteem. Thus, strong participation in international scientific gatherings similar to the IGC should be encouraged for a better understanding of our country among the rest of the world's scientists.

For more information about the USNC and its membership please visit http://www7.nationalacademies.org/usnc-iugs/. 